\title{
Se aprueba ley sobre la investigación científica en el ser humano
}

\author{
Dr. Jorge Sánchez V.
}

El día 22 de septiembre de 2006 se publicó en el diario oficial la ley No 20.120 "sobre la investigación científica en el ser humano, su genoma, y prohibe la clonación humana”.

El cuerpo legal de veintiún artículos establece un marco jurídico para tres actividades: a saber: la investigación científica y genética en seres humanos, la terapia génica y el genoma humano.

Además, prohibe la clonación de seres humanos y crea la Comisión Nacional de Bioética.

En su Artículo $1^{\circ}$, define la finalidad de dicha ley, la cual es.- "proteger la vida de los seres humanos, desde el momento de la concepción, su integridad física y psíquica, así como su diversidad e identidad genética, en relación con la investigación científica biomédica y sus aplicaciones clínicas".

En los artículos siguientes prohibe toda práctica eugenésica, salvo la consejería genética y prohíbese la clonación de seres humanos, cualesquiera que sean el fin perseguido y la técnica utilizada (Artículo $3^{\circ}$ y Artículo $5^{\circ}$ ).

Luego autoriza la terapia génica en células somáticas sólo con fines de tratamiento de enfermedades o para impedir su aparición (Artículo 7o).

Esta ley declara que el conocimiento del genoma humano es patrimonio común de la humanidad. En consecuencia, nadie puede atribuirse ni constituir propiedad sobre el mismo ni sobre parte de él. Establece también que el conocimiento de la estructura de un gen y de las secuencias totales o parciales de ADN no son patentables.

Sin embargo, precisa que "los procesos biotecnológicos derivados del conocimiento del genoma humano, así como los productos obtenidos directamente de ellos, diagnósticos o terapéuticos, son patentables según las reglas generales (Artículo $8^{\circ}$ ).
También establece que sólo se podrá investigar y determinar la identidad genética de un ser humano si se cuenta con su consentimiento previo, expreso, libre e informado, o, en su defecto el de aquél que deba suplir su voluntad en conformidad con la ley. Lo anterior es sin perjuicio de la facultad de los tribunales de justicia, en la forma y en los casos establecidos en la ley (Artículo 9०). El consentimiento deberá constar en un acta firmada por la persona que ha de consentir en la investigación, por el director responsable de ella y por el director del centro o establecimiento donde ella se llevará acabo, quien, además, actuará como ministro de fe. En todo caso, el consentimiento deberá ser nuevamente solicitado cada vez que los términos o condiciones en que se desarrolle la investigación sufran modificaciones, salvo que éstas sean consideradas menores por el Comité Ético Científico que haya aprobado el proyecto de investigación.

Precisa también la ley 20.120 que "toda investigación científica biomédica deberá contar con la autorización expresa del director del establecimiento dentro del cual se efectúe, previo informe favorable del Comité Ético Científico que corresponda, según el reglamento.

Esta ley crea (Artículo 15º una Comisión Nacional de Bioética, que estará integrada por nueve profesionales, expertos en bioética, designados por el Presidente de la República, con acuerdo del Senado adoptado por los dos tercios de sus miembros en ejercicio.

Los miembros de esta Comisión durarán cuatro años en sus cargos y podrán ser reelegidos.

El Presidente de la República, en el momento de solicitar el acuerdo del Senado, propondrá al miembro que asumirá el cargo de Presidente.

La Comisión tendrá una Secretaría Ejecutiva, que coordinará su funcionamiento y cumplirá los 
acuerdos que aquélla adopte y estará conformada por el personal que al efecto asigne el Ministerio de Salud.

Las funciones de dicha Comisión Nacional de Bioética será: asesorar a los distintos Poderes del Estado en los asuntos éticos que se presenten como producto de los avances científicos y tecnológicos en biomedicina, así como en las materias relacionadas con la investigación científica biomédica en seres humanos, recomendando la dictación, modificación y supresión de las normas que la regulen.

Las resoluciones o acuerdos de la Comisión se adoptarán por simple mayoría, no obstante lo cual deberán hacerse constar las diferencias producidas en su seno y la posición de minoría.

En los artículos siguientes (Artículo 17) establece penas para aquel que clonare o iniciare un proceso de clonar seres humanos y el que realizare cualquier procedimiento eugenésico en contravención al artículo $3^{\circ}$, así como para el (Artículo 18) que violare la reserva de la información sobre el genoma humano, y también para el que (Artículo 19) falsificare el acta a que se refiere el inciso tercero del artículo 11 y sanciona también (Artículo 20) todo el que desarrollare un proyecto de investigación científica biomédica en seres humanos o en su genoma, sin contar con las autorizaciones correspondientes exigidas por la presente ley).

Al Ministerio de Salud le corresponderá establecer, mediante reglamento, las normas que complementen o desarrollen los contenidos de la ley 20.120 .

Hasta aquí una descripción de la Ley, y surgen naturalmente algunos comentarios: Esta ley si bien aparece como un avance en nuestra legislación será letra muerta mientras no se dicte su reglamento de aplicación. Este reglamento debe precisar varios aspecto del funcionamiento de dicha ley; uno que no es menor la formación de los comités de ética en cada establecimiento.

También se puede afirmar, con poco riesgo de equivocarnos, que la designación de los miembros de la Comisión Nacional de Bioética será sometida al cuoteo político habitual. Pero surge la pregunta acerca de la efectividad que tendrá dicha comisión si no cuenta con recursos propios, salvo los que el Ministerio de Salud quiera poner a su disposición y si el trabajo de sus miembros es ad-honorem.

Esperemos que el avance que pueda significar esta ley se materialice a la brevedad y que los augurios de excesivo cuoteo político no se hagan realidad, aun cuanto la designación de los miembros del Consejo Nacional de Televisión parece indicar lo contrario. 